\title{
Influence of Plasma Transferred Arc Process Parameters on Structure and Mechanical Properties of Wear Resistive NiCrBSi-WC/Co Coatings
}

\author{
Eitvydas GRUZDYS $^{1,2}$ *, Šarūnas MEŠKINIS ${ }^{1}$ \\ ${ }^{1}$ Institute of Materials Science of Kaunas University of Technology, Savanoriu 271, LT-50131 Kaunas, Lithuania \\ ${ }^{2}$ JSC Technologija, Breslaujos 3B, LT-44403 Kaunas, Lithuania
}

Received 17 October 2010; accepted 02 November 2010

\begin{abstract}
Self-fluxing NiCrBSi and related coatings received considerable interest due to their good wear as well as corrosion resistance at moderate and elevated temperatures. Hard tungsten carbide (WC) particles can be included in NiCrBSi for further increase of the coating hardness and abrasive wear resistance. Flame spray technique is widely used for fabrication of NiCrBSi films. However, in such a case, subsequent remelting of the deposited coatings by flame, arc discharge or high power laser beam is necessary. In present study $\mathrm{NiCrBSi}-\mathrm{WC} / \mathrm{Co}$ coatings were formed using plasma transferred arc process. By adjusting plasma parameters, such as current, plasma gas flow, shielding gas flow, a number of coatings were formed on steel substrates. Structure of the coatings was investigated using X-ray diffractometry. Microstructure of cross-sectioned coatings was examined using scanning electron microscopy. Hardness of the coating was evaluated by means of the Vickers hardness tests. Wear tests were also performed on specimens to determine resistance to abrasive wear. Acquired results allowed estimating the influence of the deposition process parameters on structure and mechanical properties of the coatings.
\end{abstract}

Keywords: $\mathrm{NiCrBSi}-\mathrm{WC} / \mathrm{Co}$, self fluxing coating, plasma transferred arc deposition.

\section{INTRODUCTION}

Wear and corrosion are main problems that equipment faces in different modern industrial applications. To cut down repair costs and prolong the life of this equipment, protective coatings are applied to the surfaces under severe conditions.

One of the coating methods used for those purposes is plasma transferred arc coating process. This method stands out for its high quality, metalurgically bonded with substrate and low diluted coatings. These coatings also exhibit high homogeneity, low oxide content, and low concentrations of other unwanted inclusions. However, plasma transferred arc coating process is complex in the quantity of parameters that must be watched for the best results to be achieved. Those parameters are current, voltage, powder feed rate, gas flows, etc. By varying them, we can alter process in a way that suits materials to be coated, surface material, surface configuration [1].

There is a wide variety of materials that can be used to form protective coatings. Ni base alloys are widely used due to their outstanding oxidation, wear and corrosion resistance. These materials exhibit a high resistance to temperature. Additional elements can be added to achieve further improvement of the functional properties of these coatings. Particularly NiCrBSi is mostly used for fabrication of the wear and corrosion resistant coatings. Microstructure of these coating obtained by different process was investigated in [2].

Wear resistance of $\mathrm{NiCrBSi}$ coatings is further improved by adding hard particles, such as tungsten carbide (WC), to the nickel alloy matrix. Some papers state, that wear resistance depends on the microstructure of

\footnotetext{
*Corresponding author. Tel.: +370-37-327605; fax: +370-37-314423. E-mail address:eitvas@gmail.com (E.Gruzdys)
}

the multiphase material $[3,4]$. In some cases microstructure can be even more important than hardness. E. g., the coating structure is especially important in the case of the abrasion resistance process.

In this study the influence of plasma transferred arc process parameters such as current, plasma gas flow and shielding gas flow on the mechanical properties and microstructure of the $\mathrm{NiCrBSi}-\mathrm{WC} / \mathrm{Co}$ coatings was evaluated. Optimal set of parameters that define coatings with highest resistance to wear was determined.

\section{EXPERIMENTAL}

\subsection{Coatings formation}

Plasma transferred arc process was used to form coatings from $\mathrm{NiCrBSi}$ and $\mathrm{WC} / \mathrm{Co}$ powder on steel substrates. Castoline Eutectic Eutronic Gap device was used for that purpose. Coatings were produced using different process parameters with powder composition consisting of 30 mass percent $(\%) \mathrm{WC} / \mathrm{Co}$ and 70 mass percent $(\%) \mathrm{NiCrBSi}$. Argon was used as plasma gas as well as powder transporting gas. About $7 \%$ of hydrogen was added to the flux as a shielding gas. Process parameters are shown in Table 1. Plasma torch was stationary and the coated part was moving in a circular motion. In such a way a layer of $2 \mathrm{~mm}$ thickness was formed. Width of the coated area was $10 \mathrm{~mm}$. After formation, coatings were slowly cooled to avoid unwanted stresses.

\subsection{Analysis of Coatings Properties}

Specimens were cut perpendicular to the coating using $\mathrm{SiC}$ saw to several pieces. The microstructure analysis, hardness tests, phase composition evaluation was performed. For microstructure analysis samples were mounted 
Table 1. Plasma transferred arc process parameters

\begin{tabular}{|l|c|c|c|c|c|c|c|c|c|c|}
\hline Sample & 1 & 2 & 3 & 4 & 5 & 6 & 7 & 8 & 9 & 10 \\
\hline Current, A & 50 & 70 & 80 & 100 & 80 & 80 & 80 & 80 & 80 & 80 \\
\hline Plasma gas flow & 0.6 & 0.6 & 0.6 & 0.6 & 0.3 & 0.5 & 0.8 & 0.6 & 0.6 & 0.6 \\
\hline Shielding gas flow & 0.9 & 0.9 & 0.9 & 0.9 & 0.9 & 0.9 & 0.9 & 0.7 & 0.9 & 1.2 \\
\hline WC/Co, \% & 30 & 30 & 30 & 30 & 30 & 30 & 30 & 30 & 30 & 30 \\
\hline
\end{tabular}

and polished according to metallographic procedures. Samples were analyzed using optical and scanning electron (SEM) microscopes.

Vickers hardness was measured using PMT-3 microhardness tester. Pyramid with a tip angle of $136^{\circ}$ was pressed into surface with load of $0.1 \mathrm{~N}$. Rockwell hardness was measured by using Wilson Wolpert hardness tester 500MRA-S.

Phase composition of the coatings was evaluated using X-ray difractometer DRON-3. X-ray lamp with copper anode (characteristic wave length $\lambda=0.154178 \mathrm{~nm}$ ) 2.0BSV $-24 \mathrm{Cu}$ was used as a radiation source. The relative concentration of different crystal phases in coatings was determined by comparing intensities of different x-ray diagrams peaks. Surface morphology and structure were investigated using high resolution field emission scanning electron microscope FEI Quanta 200 FEG coupled with an energy dispersive X-ray spectrometer (EDX).

Two-body abrasive wear test was performed for each of the coatings. SiC grinding paper of grit size $120 \mu \mathrm{m}$ was used as counter abrasive. Disk was rotating at $1600 \mathrm{rpm}$. The applied load was $3 \mathrm{~N}$. Before the wear test samples were grounded to avoid surface roughness influence on experimental results. Mass loss was evaluated using weighing machine VLR-200. Accuracy of the machine is $0.05 \mathrm{mg}$.

\section{EXPERIMENTAL RESULTS}

\subsection{Microstructure and phase composition}

During NiCrBSi-WC/Co(30 \%) plasma transferred arc coating process shielding gas flow was varied. Fig. 1 shows X-ray diffraction spectrum of coatings produced using three different values of flow. Nickel peaks are most noticeable in all cases. At $0.7 \mathrm{l} / \mathrm{min}$ and $0.9 \mathrm{l} / \mathrm{min}$ flows these peaks are slightly wider, especially at $2 \theta$ values of $75^{\circ}$ and $92^{\circ}$. It seems that increased shielding gas flow results in increased temperature of the plasma torch and also the crystallization of the nickel [5].

Both, tungsten carbide compounds $\mathrm{WC}$ and $\mathrm{W}_{2} \mathrm{C}$, and tungsten $\mathrm{W}$ crystalline phases do not seem to be influenced much by changing shielding gas flow. Just in the case of the highest flow, WC peaks are less intensive. It is related to the fact that at higher temperatures that compound tends to decarburize.

Temperature of the torch increases with the increase of the plasma current. If the current is too low, plasma energy may not be enough to fully melt powder particles. In this case, there is a possibility for a poor adhesion with the substrate. According to Fig. 2, a, b, one can see that $\mathrm{WC} / \mathrm{Co}$ particles sustained their form and the boundary between tungsten carbide and alloy matrix is clearly visible. It is an indication that torch temperature was not enough to melt carbide. Further increase of the plasma current results in dissolvation in matrix. Some particles stay in agglomerated formations, while other particles remain in agglomerated formations.

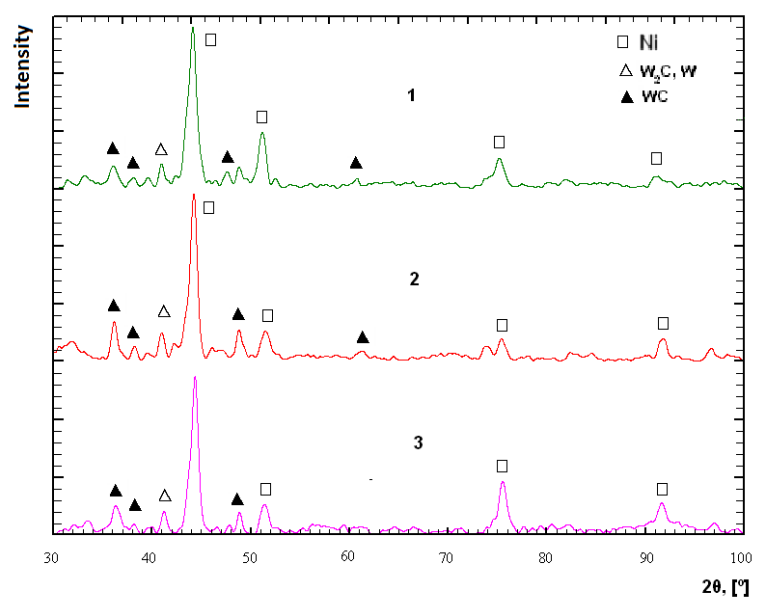

Fig. 1. XRD spectra of $\mathrm{NiCrBSi}-\mathrm{WC} / \mathrm{Co}(30 \%)$ coatings produced with plasma transferred arc process using different shielding gas flows: $1-0.7 \mathrm{l} / \mathrm{min} ; 2-0.9 \mathrm{l} / \mathrm{min}$; $3-1.2 \mathrm{l} / \mathrm{min}$

According to Fig. 2, d, one can see that in the case of highest plasma current $(100 \mathrm{~A})$ tungsten carbide particles can be hardly detected. It means, that WC was fully melted in NiCrBSi matrix. Studies by other authors revealed similar results $[6,7]$. WC full melting in NiCrBSi matrix was observed in our previous research as well [8].

Three different samples were coated using different plasma gas flows. In this case argon was used as a plasma gas. Flows were $0.3 \mathrm{l} / \mathrm{min}, 0.5 \mathrm{l} / \mathrm{min}$ and $0.8 \mathrm{l} / \mathrm{min}$ respectively. As it can be seen in Fig. 3, at low plasma gas flows plasma torch is less concentrated and the energy is enough only for smallest carbide particles to be dissolved in the matrix. Bigger particles dissolve just partially or just change their initial form. The torch becomes more constrict and hotter with increase of the gas flow [9]. In this case bigger portion of tungsten carbide particles are molten. When plasma gas flow reaches $0.8 \mathrm{l} / \mathrm{min}$ just a small fraction of tungsten carbide stays unmolten.

Energy dispersive X-ray analysis was performed on coatings to define elemental composition of different characteristic zones in its cross-section. As it was expected, spectrum of white sharp shaped particles shows high amounts of tungsten (Fig. 4, a). It is unmelted tungsten carbide also seen in Fig. 2, a. Though material powder has a small amount of iron in it, EDX spectrum shows a value of $20 \%$. That can indicate that during coating 


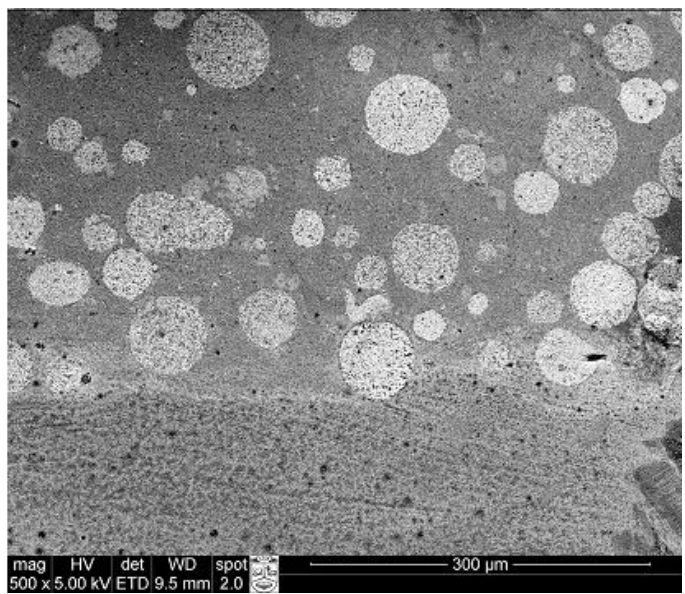

a

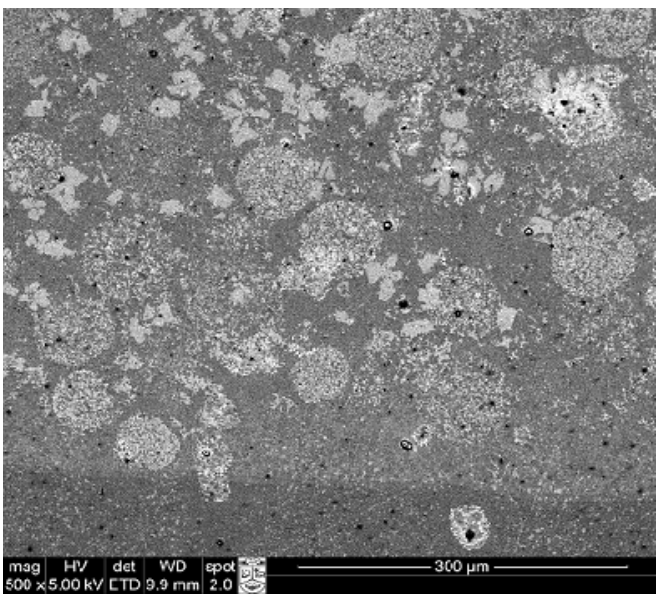

c

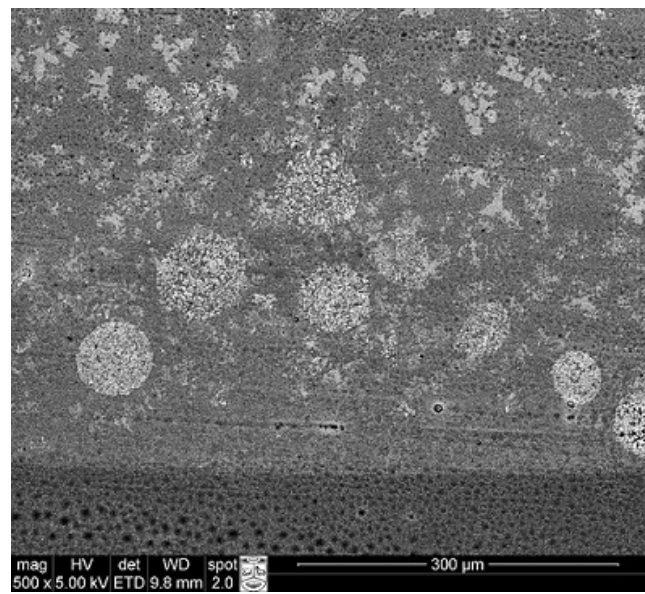

b

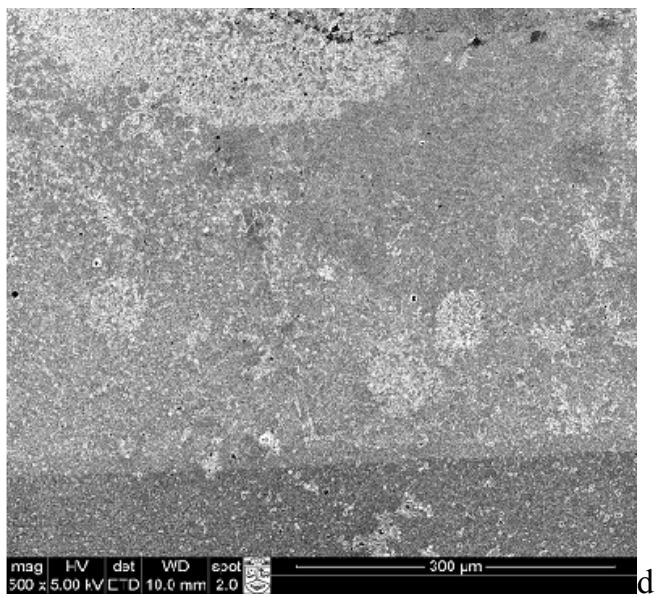

d

Fig. 2. $\mathrm{NiCrBSi}-\mathrm{WC} / \mathrm{Co}(30 \%)$ microstructure with plasma current: $\mathrm{a}-50 \mathrm{~A} ; \mathrm{b}-70 \mathrm{~A} ; \mathrm{c}-80 \mathrm{~A} ; \mathrm{d}-100 \mathrm{~A}$

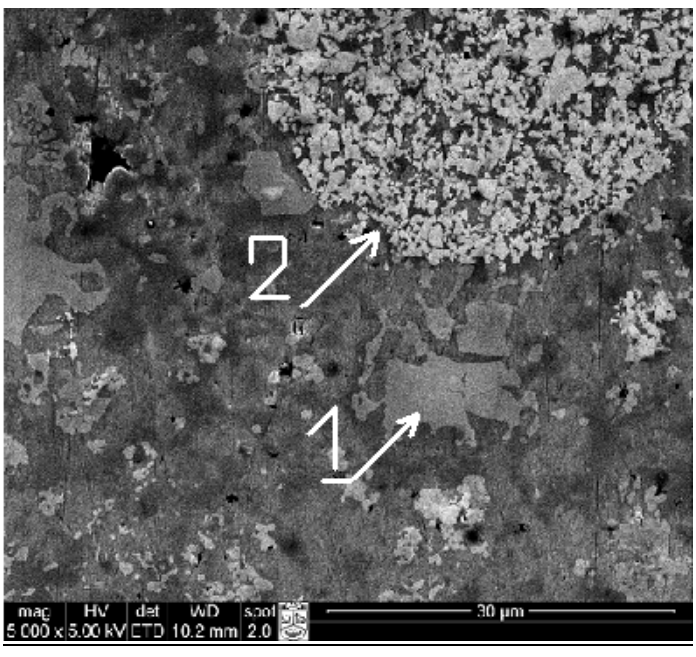

Fig. 3. $\mathrm{NiCrBSi}-\mathrm{WC} / \mathrm{Co}(30 \%)$ microstructure; plasma gas flow $0.3 \mathrm{l} / \mathrm{min} ; 1$ - molten carbide; 2 - unmolten carbide

process some diffusion of the iron from the steal substrate into the coating took place. Analysis of big white regions in the matrix shows similar composition as in the case of sharp shaped particles: high peak of tungsten, the same amounts of the chromium. Difference is in nickel and iron quantity. Those regions correspond to molten tungsten carbide. Energy dispersive X-ray analysis of alloy matrix

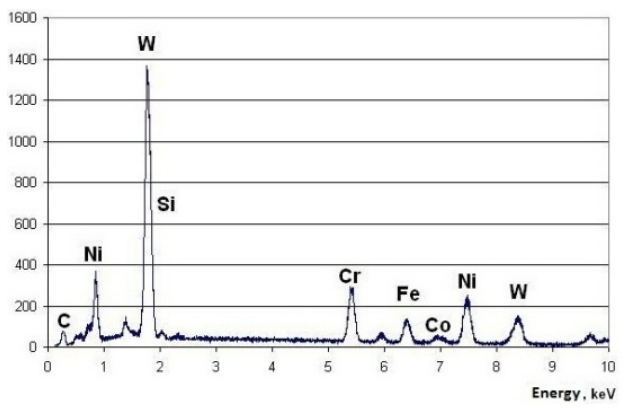

a

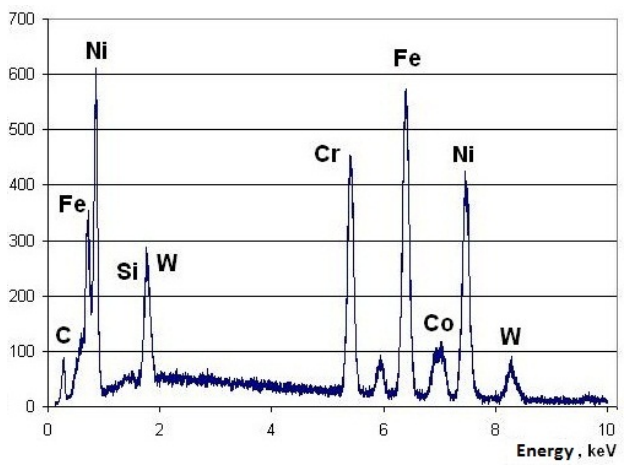

b

Fig. 4. EDX spectra of: $\mathrm{a}$ - unmelted WC; $\mathrm{b}$ - alloy matrix 
shows considerably lower amounts of tungsten. Nickel, chromium and iron are predominant here. There are also signs of carbon, silicon and cobalt (Fig. 4, b).

\subsection{Mechanical properties}

Rockewell hardness of the coatings as well as hardness distribution across the cross-section of selected samples was measured (Figs. 5, 6). Rockwell hardness of the NiCrBSi-WC/Co coated samples was nearly twice higher than hardness of the steel substrate. However, only minor differences was observed for the samples coated using different discharge currents (Fig. 5).

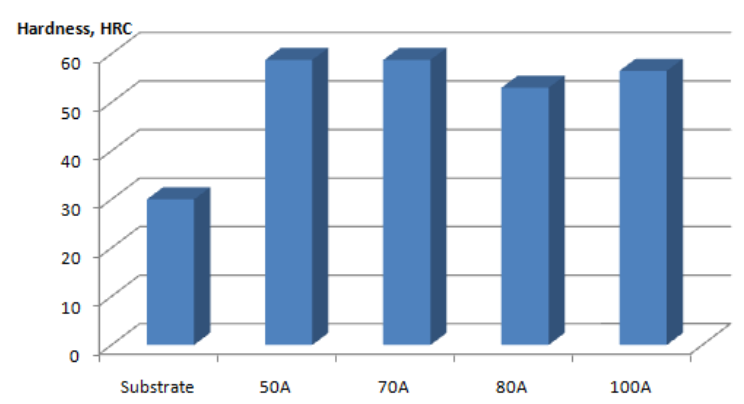

Fig. 5. Rockwell macrohardness for coatings formed using different current

Multiple microhardness values were acquired by measuring from the surface of the coating to the substrate (Fig. 6). These values vary across the cross section. That is because indenter can get on hard tungsten carbide particle or relatively soft alloy matrix. Measurement showed that coating produced using $100 \mathrm{~A}$ current had average hardness value of $300 \mathrm{HV}$. That can be explained by the fact that at $100 \mathrm{~A}$ current plasma temperature is high enough to fully dissolute most of tungsten carbide to alloy matrix or for it to undergo phase transformation from WC to $\mathrm{W}_{2} \mathrm{C}$, which is more brittle $[10,11]$. Because of this transformation, wear resistance is also lower than in the case of $80 \mathrm{~A}$ (Fig. 7). Comparing microhardness of coatings produced using $50 \mathrm{~A}$ and $80 \mathrm{~A}$ plasma current, it can be seen that in the case of the lower current, microhardness changes just slightly across the cross section of the coating. High hardness values correspond to the tungsten carbide particles, which is around $700 \mathrm{HV}$ and lower ones to alloy matrix hardness, around $400 \mathrm{HV}$. In the case of $80 \mathrm{~A}$ current, variations in hardness are higher and average value is about $300 \mathrm{HV}$.

\section{CONCLUSIONS}

In conclusion $\mathrm{NiCrBSi}-\mathrm{WC} / \mathrm{Co}$ coatings were fabricated using different parameters of plasma transferred arc process. The influence of the plasma current, shielding gas flow and initial powder composition was considered. Microstructure analysis revealed higher carbide dissolution at higher plasma current and shielding gas flow. It was explained by increase of the plasma temperature with discharge current and shielding gas flow. It also defines lower values of microhardness. Decreased hardness of the coatings was explained by dissolution of the carbides at high temperature. Shielding gas flow variations resulted in

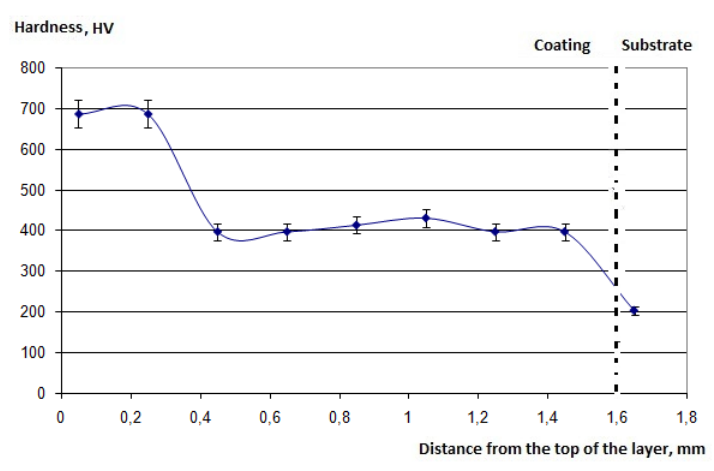

a

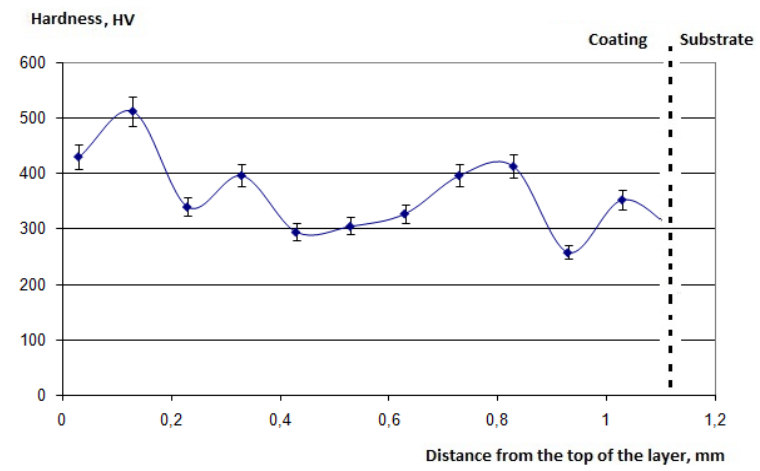

b

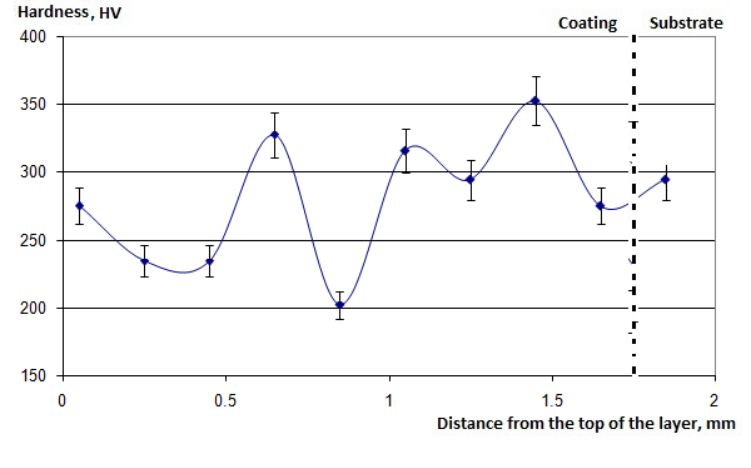

c

Fig. 6. Microhardness change in the cross section of the coatings. Plasma current: $\mathrm{a}-50 \mathrm{~A}, \mathrm{~b}-80 \mathrm{~A}, \mathrm{c}-100 \mathrm{~A}$

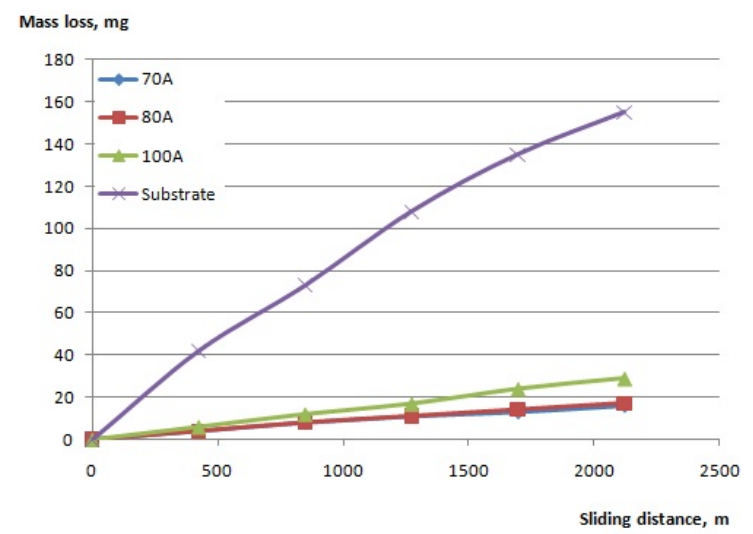

Fig. 7. Resistance to abrasive wear of the coatings formed using different plasma current

only slight change of the phase composition of the coatings. Abrasive wear resistance depended on microstructure of the coatings, while no correlation with hardness was observed. 


\section{Acknowledgments}

Authors would like to thank T. Tamulevičius (from Kaunas University of Technology) for SEM and EDX measurements.

\section{REFERENCES}

1. Gatto, A., Bassoli, E., Fornari, M. Plasma Transferred Arc Deposition of Powdered High Performances Alloys: Process Parameters Optimisation as a Function of Alloy and Geometrical Configuration Surface and Coatings Technology 187 2004: pp. 265-271.

2. González, R., García, M. A., Peñuelas, I., Cadenas, M., del Rocío Fernández, Ma., Hernández Battez, A., Felgueroso, D. Microstructural Study Of Nicrbsi Coatings Obtained By Different Processes Wear 2632007 : pp. $619-624$.

3. Buchanan, V. E., Shipway, P. H., McCartney, D. G. Microstructure and Abrasive Wear Behavior of Shielded Metal Arc Welding Hardfacings Used in the Sugarcane Industry Wear 263 2007: pp. 99-110.

4. Buchely, M. F., Gutierrez, J. C., Leon, L. M., Toro, A. The Effect of Microstructure on Abrasive Wear of Hardfacing Alloys Wear 259 2005: pp. 52-61.

5. Sidhu Buta Singh, Puri, D., Prakash, S. Mechanical and Metallurgical Properties of Plasma Sprayed and Laser
Remelted Ni-20Cr and Stellite-6 Coatings Journal of Materials Processing Technology 159 2005: pp. 347-355.

6. Harper, D., Gill, M., Hart, K. W. D. Plasma Transferred Arc Overlays Reduce Operating Costs in Oil Sand Processing International Thermal Spray Conference 2002, Essen, Germany, 2002.

7. D'Oliveira, Tigrinho, J. J., Takeyama, R. R. Coatings Enrichment by Carbide Dissolution Surface and Coatings Technology 202 2008: pp. 2660-2665.

8. Gruzdys, E., Meškinis, S., Juraitis, A. Influence of WC/Co Concentration on Structure and Mechanical Properties of the Thermally Sprayed WC/Co-NiCrBSi Coatings Materials Science (Medžiagotyra) 15 (1) 2009: pp. 35-39.

9. Vardelle, A., Fauchais, P., Dussoubs, B., Themelis, N. J. Heat Generation and Particle Injection in a Thermal Plasma Torch Plasma Chemistry and Plasma Processing 18 (4) 1998: pp. $551-574$

10. Stoica, V., Ahmed, R., Itsukaichi, T. Influence of Heattreatment on the Sliding Wear of Thermal Spray Cermet Coatings Surface and Coatings Technology 199 2005: pp. 7-21.

11. Morks, M. F., Gao Yang, Fahim, N. F, Yingqing, F. U. Microstructure and Hardness Properties of Cermet Coating Sprayed by Low Power Plasma Materials Letters 60 2006: pp. 1049-1053. 